\title{
Reseña. María Soledad Boero. Trazos impersonales. Jorge Barón Biza y Carlos Correas. Una mirada heterobiográfica. Eduvim, 2017.
}

El libro es abierto por su autora con una idea condensada en el epígrafe de Hölderlin que antecede a los agradecimientos: "Es bueno sostenerse sobre otros. Porque nadie lleva en soledad la vida". Cita que se vuelve un gesto si pensamos que, con esa cita, más que cumplir con las convenciones de rigor que en el género académico se estilan, María Soledad Boero desestabiliza las pertenencias entre el nombre propio, la firma autorial y el saber escrito, al hacer atravesar por ese lazo a una red de escrituras de la amistad. El lugar para inscribir en la escritura una vida estable y definida (la primera persona que remite a un yo que investiga, escribe y firma) se ve desestabilizado con la apertura que convoca trazos de otros yoes, trazos más del orden de los afectos que de un saber.

Queremos resaltar este gesto apertural porque es precisamente el desmontaje de la correspondencia entre la obra y la vida, la persona y su escritura, el trazo y la experiencia, lo que el libro, que primero fue una tesis doctoral, explora al analizar la literatura de Jorge Barón Biza y Carlos Correas. La pregunta incisiva que le hace Boero a la fe en el yo soberano, completo y representable de la autobiografía moderna es por las posibilidades de escribir la vida: ¿cómo escribir 
la propia vida para volverla obra, si no existe algo así como una vida propia o una obra acabada? Mediante las obras de ambos autores, la vida es descubierta y hasta puesta en valor, transgrediendo una literatura convencional que aleja al yo narrador del yo autoral para hacer hincapié en lo ficcional. Así, se produce un desmontaje entre la vida y la obra autobiográfica que al mismo tiempo que descree de la posibilidad de narrar al yo como totalidad, insiste en explorar esa vida ahuecada, porque es precisamente en esos huecos que interrumpen la linealidad de lo escrito donde aparece la posibilidad de una vida "ajena a las formas de la propiedad" (46).

Después de la efervescencia de las escrituras del yo que presenciamos en la escena crítica argentino-latinoamericana reciente y que la crítica acogió con frases como "giro autobiográfico", "performance de autor", "era de la intimidad", "espacio subjetivo", "espacio biográfico", Boero se detiene a desarmar conceptos que damos por naturalizados en la palabra autobiografía y que no alcanzan para nombrar ciertas poéticas en primera persona: auto, bíos, grafía. En esta pausa desconfiada del "imperio del yo" (37) radica su apuesta atenta y minuciosa: en interrumpir a la matriz autobiográfica con vidas (bíos) que no se reducen al yo que pueda dar cuenta de sí mismo (autos) pero que no obstante se ponen en obra (grafía). No solo para mostrar una insuficiencia de ciertos conceptos establecidos para pensar las poéticas de Correas y Barón Biza, sino también para crear un lenguaje crítico que las nombre no con propiedad -resguardando el resto de lo intraduciblepero sí con la mayor cercanía posible.

Si la matriz autobiográfica no puede dar cuenta de las fisuras del yo, se trata de explorar las escrituras no yoicas de Correas y Barón Biza. Razón por la que Boero realiza un movimiento innovador que no va de la teoría a la literatura -si pudiéramos trazar tales límites- sino de la literatura a la teoría, y rescata de la obra de Correas el concepto de "heterobiografia" para convertirlo en un aparato crítico que da cuenta de escrituras preocupadas por "volver contable la vida" pero más allá de los límites del yo y de las obras modernas. El material biográfico son los fragmentos de vidas no necesariamente identificables con la de un sujeto, que la escritura no compone en una sucesión lineal y acabada sino desmontándolo al 
marcar la presencia de ajenidades, huecos, afueras. Una escritura que descree de la posibilidad de ese movimiento sobre sí implícito en el "autos" sin pasar primero por la ajenidad del encuentro con lo otro, la lengua y el afuera.

Lejos de la intención de volver a lo heterobiográfico una cualidad esencial de los textos, Soledad lo propone más bien como una mirada -o un adjetivo que precisa a la escritura sin encerrarla- que se fuga de las figuras de identidad, persona, humano, porque se trata más bien de vidas que se resisten a ser apropiadas por un sujeto definible por los marcos de un yo soberano. En palabras de la autora:

La heterobiografía, tal como venimos señalando, más que una trayectoria de vida, lo que intenta es mostrar la dificultad de mantener esa ilusión de trazado, de cronología de una vida; además de poner en revisión la primera persona que asume el yo como el principal operador en la narración de la experiencia vivida, ya que lo "contable" de una vida excedería en gran medida lo que una mirada humana puede percibir, lo que una identidad del yo bajo la máscara de la persona puede narrar. (25)

La escritura ya no puede dar cuenta de un sujeto, y en esa oscilación entre lo propio y lo inapropiable se genera el movimiento de la desobra, hacia aquellos fragmentos de vida que se resisten a ser ordenados en la conformación lineal de una obra.

Por eso, la escritura heterobiográfica oscila entre una "estética de la desobra" y una "ética de la subjetividad". Los conceptos de sujeto que escribe y escritura que lo representa se ven extrapolados, Blanchot, Deleuze, y Nancy mediante, hacia los de una vida que no se reduce a los límites de un yo -sujeto desobrado y exiliado-, y una obra que desarma las ilusiones de homogeneidad e inmediatez de la estética moderna, -desobra-. Y el vínculo entre ambos se vuelve el trazo impersonal de un dibujo que tiende hacia lo informe y lo inacabado y que arrastra la vida por fuera de la máscara de la persona, que "libera al yo de su investimento personal abriéndolo a otras dimensiones vitales no humanas" (49). 
Porque para los narradores en cuestión, lo propio es fundado a partir de lo ajeno y subyace así la pregunta acerca de cuáles son los límites entre "lo propio", "lo ajeno" o "lo común".

No es aleatorio que Boero elija tomar posturas como las de Nancy para revisar lo propio de una experiencia y sus modos de representación en la escritura, pensando desde la condición de exilio (45). La necesidad de demostrar un desfondamiento del yo para representar una vida que ya no pertenece a la persona es lo novedoso y apreciativo del análisis. De allí la tendencia hacia lo inacabado y lo informe de la práctica escritural de Barón Biza y Correas que mencionábamos. Hay un proceso de desubjetivación que nos permite pensar aquello que se torna singular, a modo de experiencia de lo impersonal: los autores abordados por Boero se vinculan entre sí no solo por la forma escritural que los retrata, sino además porque ambos han transitado, en su intimidad vivencial experiencias que solo la escritura les ha permitido desarrollar. Por eso es también que resulta productivo el desarrollo del concepto de singularidad para pensar los vínculos establecidos entre el sujeto de la escritura y el modo en que se concibe la experiencia.

Los "yo" a los que Boero refiere ponen el cuerpo para hacerse o (des)hacerse con la escritura, narrando desde las experiencias y circunstancias propias y ajenas ${ }^{1}$-la de la desfiguración del rostro de su madre, en el caso de Barón Biza, y el deambular y transitar por lo urbano con una sexualidad que irrumpe los límites de una vida en el caso de Correas-. Ningún resto es descartado, porque en la escritura y especialmente en esta escritura singular, se requiere de varios matices que aporten a la configuración del relato fragmentado. No solo en términos biográficos narrativos, sino también en términos en los que la escritura se transforma en una herramienta de subjetivación para sostener y testimoniar el desfondamiento del yo.

${ }^{1}$ Siguiendo a Miraux, Boero coincide también en que en un proyecto "autobiográfico", la existencia se transforma en escritura, sumado a un deseo de narrar lo experiencial de una vida (Ver página 122). 
A modo de resumen, podríamos decir que en Trazos impersonales... Boero repiensa a partir de la (des)obra de Barón Biza y Correas los modos de desubjetivación que ponen en juego la ausencia de lo propio y vuelven a la escritura un espacio de inscripción de aquello que escapa a la identidad personal y un medio potente para esbozar lo que ya ha perdido su forma, no encontrando el modo de ser representado. El planteo de todo el abordaje crítico-metodológico que Boero desarrolla, se convierte en un importante trabajo investigativo que señala que la narración no solo aporta datos íntimos sino que además recrea diferentes momentos históricos, lo cual hace oscilar la vida de Correas, Baron Biza y sus obras entre la autobiografía $^{2}$ y libro de memorias. Surgen así los interrogantes: “¿Cuándo comienza la vida y cuándo se conecta con la narración?, ¿podríamos suponer que la vida "propia" surge en el momento de la escritura?" (p. 69).

El caso de Correas, el análisis, centrado en el cuento "La narración de la historia”, en Los reportajes de Félix Chaneton y Operación Masotta, sigue la línea trazada por la pregunta que el escritor se hace acerca de los modos de volver la vida contable: de cómo capturar con la escritura los destellos de la vida que no se organiza en la temporalidad nazco-crezco-muero sino en el presente de la experiencia que se desarma en "retazos de vida que no terminan de darse". El dispositivo heterobiográfico se activa cuando la narración marca los desvíos del recorrido del yo hacia la exterioridad de una vida biografiable, recorrido que Correas insiste en transitar al mismo tiempo que lo erosiona y lo desmonta. Interesan los modos que utiliza para no hablar de lo íntimo, narrando que lo "experiencial" que le pertenece sea, justamente lo que interesa retratar. Entonces, desde aquí Boero nos muestra cómo Correas hace ingresar la matriz heterobiográfica de lo nuevo en una continua actitud de desobra, dando lugar a matices de desubjetivación para explicar y expresar que escribir sobre sí mismo implica separarse de lo demás. Tal es el caso de Barón Biza cuando describe el rostro de su madre como superficie donde la escritura es lo que da forma o deforma

\footnotetext{
${ }^{2}$ Sin olvidar que Baron Biza sostiene que lo autobiográfico puede resultar peligroso.
} 
los caminos de lo propio y de lo impropio, conformando una subjetividad puramente escritural.

En lo que refiere entonces a Barón Biza, el ojo está puesto en la única novela publicada por el escritor: El desierto y su semilla (1998), escrita desde un lugar periférico al campo intelectual de su época y extrañamente ignorado por la crítica, que relata el episodio biográfico de la desfiguración del rostro materno en un episodio de violencia por parte de su padre y su posterior reconstrucción. La pregunta surge en torno a la posibilidad de figurar a través de la escritura aquello que ya no es representable porque, al haber sido despojado de toda marca de identidad personal primera, el rostro, se abre hacia el ámbito de lo prehumano y lo prelingüístico. Por eso mismo, más que una apropiación la acción de escribir implica una apertura a lo desconocido de los signos que va inventando -con la recurrencia al cocoliche- y a la ajenidad de una experiencia no propia que se testimonia y vive. Para Barón Biza, la autobiografía, más que certezas sobre el yo consiste en el movimiento de "dejarse habitar por esa desfiguración que viene de otro lugar":

La invención (dirá Boero) apela a fabricar un espacio allí donde no lo había, a trazar una línea donde antes no se encontraba nada, una invención que deja entrever la existencia de componentes que van más allá del yo. (155)

Nos percatamos sobre los modos en los que los relatos de los escritores estudiados transgreden los límites del campo de lo decible. En el caso de Correas, la autora detecta cómo en el plano de las prácticas existe un circuito en el cual se desarrollaban diferentes conductas sexuales que en el plano del discurso permanecen obliteradas. La de Correas, es una vida que vibra al ritmo de las experiencias transitadas en la ciudad y la de Barón Biza una vida enlazada desde su infancia con el sinsentido de la tragedia familiar de su madre, horror que le impide encontrar el signo que trace la historia de su vida, por un lado, pero que por otro le genera extrañeza con su nombre propio, heredado del padre. Es por eso que la 
escritura se transforma en excritura, línea precaria que bordea los límites del lenguaje con los del yo.

El análisis nos lleva a cuestionarnos: ¿qué vida es la que se quiere contar, recordar o hacer vivir? Y por otro lado: ¿cómo transformarla en obra? Quizás aquella en donde la experiencia queda abierta y no se termina de cerrar para dar lugar a otras actualizaciones temporales, ya que lo que se actualiza tiene que ver con lo vivible, eso que permanece en el plano virtual pero no deja de ser real. La autora se detiene en el interés principal de Barón Biza, interés que tiene que ver con fusionar una búsqueda desde los restos, fragmentos y cenizas para componer una voz y sostener un yo, siempre frágil y desconocido, mediante la escritura. Y otro yo, en el caso de Correas, que con su escritura enmarca las experiencias vividas desde lo íntimo y, desde su amistad con Oscar Masotta por ejemplo, para rearmar y configurar pautas sobre cómo concebir lo "biográfico" que incluye lo anecdotario.

Desde este lugar es que Boero trabaja con dichos autores porque hacer "experiencias" no solo tiene que ver con lo efectivamente "vivido" sino con llevar a un extremo aquello que todavía no se vivió, ligado a lo que puede llegar a ser, pero que aun no se da. Lo escritural atiende y prefigura una vida inacabada para explorar posibilidades no solo desde "un otro", sino -fundamentalmentetransformando a lo otro en uno mismo. Es arduo el abordaje y el anclaje que Boero decide dar a las obras literarias trabajadas, investigación que no es azarosa y que nos permite observar que una vida o varias vidas se pueden narrar desde la singularidad y desde la transitoriedad del "yo", necesaria para poder determinar qué de nosotros existe en los otros y qué es funcional a nuestra propia experiencia de escritura.

Este trabajo resulta una excelente propuesta para repensar lo rutinario de nuestras experiencias que, en ocasiones, suelen pronunciarse desde las voces de otros y no desde la propia voz; olvidando que existe un desmontaje capaz de transformar a la escritura en /medio que sostiene circunstancias donde se evita el 
defondamiento de un "yo", logrando así que lo impersonal emerja para ser salvado, justamente, gracias al acto de escribir. 